\title{
The Dependence Structure of Macroeconomic Variables in the US
}

\author{
Lorán Chollete and Cathy Ning*
}

September 17, 2009

\begin{abstract}
A central role for economic policy involves reducing the incidence of systemic downturns, when key economic variables experience joint extreme events. In this paper, we empirically analyze such dependence using two approaches, correlations and copulas. We document four findings. First, linear correlations and copulas disagree substantially about the nation's dependence structure, indicating correlation complexity in the US economy. Second, GDP exhibits linear dependence with interest rates and prices, but no extreme dependence with the latter. This is consistent with the existence of liquidity traps. Third, GDP exhibits asymmetric extreme dependence with employment, consumption and investment, with relatively greater dependence during downturns. Fourth, money is neutral, especially during extreme economic conditions.
\end{abstract}

Keywords: Asymmetric dependence; Copula; Correlation Complexity; Extreme Event; Economic Policy; Money Neutrality; Systemic Downturn

JEL Classification: C14, E20, E30, E40

${ }^{*}$ Chollete is at the University of Stavanger, email Loran.Chollete@nhh.no. Ning is at Ryerson University, email qning@ryerson.ca. Chollete gratefully acknowledges support from Finansmarkedsfondet Grant \# 185339. Chollete is the corresponding author. Address: Faculty of Social Sciences, Department of Business Administration University of Stavanger NO-4036 Stavanger, Norway. Ph: (47) 5183 3701. Fax: (47) 5183 1550. 


\section{Introduction and motivation}

When a national economy experiences high dependence across important markets after a negative shock, this indicates a severe downturn 1 The experience of crises in the 1990s and 2000s has stimulated researchers' interest in measuring dependence of extreme events in the US economy 2 A further aspect of macroeconomic dependence is that it amplifies the impact of surprise events 3 For example, the collapse of a major lending institution affects many households, and can cause total insurance claims to increase geometrically, since multiple classes are affected, including property loss and job loss 4 The lack of empirical research on such "simultaneous hard times" means that individuals and society are not prepared, when such preparation matters most. Dependence is also important from a theoretical perspective, since it indicates strategic complementarities 5 Macroeconomists have therefore devoted considerable research effort to examine dependence of key national economic variables 6 Most empirical and theoretical studies consider average dependence, which is appropriate if the true dependence structure is linear. However, when dependence is nonlinear, it is important to use robust dependence measures 7 Recently there have evolved robust tools to study dependence, such as copulas 8 . While such tools have been applied successfully in banking and finance, there is no comparable research on a national economy. In light of the above considerations, we investigate dependence in the US macroeconomy, using both correlations and a parsimonious copula function. We also discuss implications for economic modeling and policy.

\footnotetext{
${ }^{1}$ For evidence on welfare costs of economic downturns, see Chatterjee and Corbae (2007), Barro (2009), and the references therein.

${ }^{2}$ Throughout, we use the word dependence as an umbrella to cover any situation where two or more economic variables move together. This terminology follows statistical literature such as Drouet Mari and Kotz (2001); and Embrechts, McNeil, and Straumann (2002). We adopt this practice because there are numerous words used in economics (e.g. coherence, correlation, concordance, co-dependency, co-movement, and procyclicality), and we wish to use a general term. We do not assume that any dependence measure is ideal, and throughout we indicate advantages and disadvantages as the case may be.

${ }^{3}$ See Horst and Scheinkman (2006), and Krishnamurthy (2009) for economic explanations of such amplifications.

${ }^{4}$ For details on insurance during periods of macroeconomic dependence, see Jaffee and Russell (1997); Jaffee (2006); and Ibragimov, Jaffee, and Walden (2009b) .

${ }^{5}$ See Wilson (1975); Bikhchandani, Hirschliefer, and Welch (1992); Cooper (1999); Veldkamp and Wolfers (2007); and Vives (2008), chapter 6.

${ }^{6}$ See Keynes (1936); Burns and Mitchell (1946); Phillips (1958); Phelps (1968); Lucas and Rapping (1969); Long and Plosser (1983); Hamilton (1983); Hamilton (2001); Granger (2001); and Phelps (2007).

${ }^{7}$ See Granger (2001); Hamilton (2001); and Embrechts, McNeil, and Straumann (2002).

${ }^{8}$ These tools are drawn from distributional and asymptotic approaches in statistics. For distributional approaches see Embrechts, McNeil, and Straumann (2002); Joe (1997); and Nelsen (1998). For asymptotic approaches see Embrechts, Kluppelberg, and Mikosch (1997); and de Haan and Ferreira (2006).
} 
The main goal of this paper is to assess the dependence structure of major economic variables in the US economy. The recent history of the US economy is interesting in itself, due to the economic crisis, increasingly globalized markets, and spillovers between financial and labor or product markets 9 A secondary focus of our paper is the relation between dependence and systemic stability. In general, systemic instability increases with the degree of market dependence, as observed by Caballero and Krishnamurthy (2008); Ibragimov, Jaffee, and Walden (2009b), and Shin (2009), among others. Systemic instability may also be exacerbated by correlation complexity, when different dependence measures give conflicting or inaccurate signals. It is therefore vital for households, banks and policymakers to have accurate estimates of dependence. There are several measures available in economics, including the traditional correlation and copulas. While each approach has advantages and disadvantages, they rarely have been compared in the same empirical study. Such reliance on one measure prevents easy assessment of the degree of dependence, and how it differs over time or across markets. The importance of this issue is highlighted by both theoretical and applied research 10 When economic variables' distributions are heavy tailed, they may suggest a wedge between acceptable individual risk and systemic risk. Thus, there are aggregate ramifications for elevated levels of economic dependence. If systemic costs are too severe, a coordinating agency may be needed to improve the economy's resource allocation 11 Such policy considerations are absent from most previous empirical research on nonlinear dependence of economic variables, and provide a further motivation for our paper.

There is a long literature examining dependence in the macroeconomy, including research on output-inflation tradeoffs, money neutrality, consumption-income relations, business cycle comovements, investment and taxes, and policy effectiveness 12 Such dependence is rarely innocuous. It is appealing in the case of valuable policy tradeoffs such as the original Phillips curve. Alternatively, it can be unappealing when it indicates economic fragility or inefficiency 13 Despite the clear policy and academic relevance, little existing research examines nonlinear dependence. Therefore our research fills a much-needed role,

\footnotetext{
${ }^{9}$ See Acharya and Richardson (2009); Brunnermeier (2009); Reinhart (2008); and Reinhart and Rogoff (2009).

${ }^{10}$ See Rosenberg and Schuermann (2006); Ibragimov, Jaffee, and Walden (2009b); and Shin (2009).

${ }^{11}$ For related work, see Caballero and Krishnamurthy (2008); Ibragimov, Jaffee, and Walden (2009a); and Shin (2009).

${ }^{12}$ See Keynes (1939); Phillips (1958); Hall and Jorgenson (1967); Friedman (1968); Phelps (1968); Lucas and Rapping (1969); Kydland and Prescott (1982); and Hansen (1985).

${ }^{13}$ See Feldstein and Horioka (1980).
} 
by documenting the type of dependence in the US economy during normal and extreme periods.

The remaining structure of the paper is as follows. In Section 2 we review theoretical and empirical literature on macroeconomics and dependence. In Section 3 we compare and contrast dependence measures used in economics. Section 4 discusses our data and main results, and Section 5 concludes.

\section{Macroeconomic dependence and systemic risk}

It has long been observed that important macroeconomic variables exhibit dependence (comovement), in modern capitalist economies. This notion appears in macroeconomics, labor and public economics. The seminal paper of Lucas (1977) emphasizes that a principal feature of macroeconomic cycles concerns "co-movements among various aggregative time series" 14 This feature is so pronounced that "with respect to ... co-movements among series, business cycles are all alike" 15 Similarly, Long and Plosser (1983) underscore that "The term 'business cycles' refers to the joint time-series behavior of a wide range of economic variables such as prices, outputs, employment, consumption and investment"16 A central precept is therefore that business cycles exhibit a recognizable dependence structure between key variables 17 An important caveat, noted as early as Keynes (1936), concerns nonlinearities in dependence, such as the liquidity trap, and asymmetric booms and busts 18 These nonlinearities are not only of theoretical interest, they also impinge on the effectiveness of macroeconomic policy. This importance of dependence structure motivates our use of nonlinear, rank-based models in our empirical analysis.

\footnotetext{
${ }^{14}$ Lucas (1977), page 9.

${ }^{15}$ Lucas (1977), page 10. Economic variables that tend to exhibit dependence with GDP include prices, interest rates and monetary aggregates.

${ }^{16}$ See Long and Plosser (1983), page 39. Both Long and Plosser (1983) and Lucas (1977) state that the the dependence structure of macroeconomic variables is inherent in the definition of business cycles. In similar fashion Sargent (1979), page 212, states that "an important feature of business-cycle phenomena is high pairwise coherences at low business cycle frequencies..." Here coherence denotes statistical dependence.

${ }^{17}$ Aspects of this precept have been examined or formalized by Keynes (1936); Burns and Mitchell (1946); Phillips (1958); Phelps (1968); Lucas and Rapping (1969); Lucas (1972); Lucas (1977); Minsky (1982); and Long and Plosser (1983). More recent theoretical models of dependence rely on strategic complementarities, see Bikhchandani, Hirschliefer, and Welch (1992); Cooper (1999); and Vives (2008).

${ }^{18}$ Asymmetries have been documented in output growth, since output has long periods somewhat above trend, then brief periods far below. See De Long and Summers (1986).
} 
When economic variables have substantial nonlinear dependence in their tails, standard regression and correlations may be biased and inefficient. That is, correlations do not accurately represent the true dependence structure 19 From an economic perspective, such nonlinearities are very important. Two that are of interest are liquidity traps, and the Phillips curve. In an early study, Keynes (1936) discusses liquidity traps. These occur if the nominal interest rate is very low. In such cases there is little opportunity cost of holding money, so individuals can change their money holdings regardless of the interest rate. This elasticity of money demand means that individuals do not respond to prices. Hence, from an aggregate perspective monetary policy is ineffective, and aggregate demand completely determines output. For more normal periods when interest rates are higher, the dependence between equilibrium output and prices is negative 20 Keynes (1936) underscores the need for avoiding such nonlinearities. In a discussion preceding the modern Phillips curve, Keynes (1939) discusses the lack of consensus on the dependence structure of real wages and output. Related work by Hamilton (2001) shows that nonlinearities are important for explaining the Phillips curve. More broadly, Granger (2001) and Phelps (2007) emphasize the likelihood of subtle, fundamental nonlinearities in modern capitalist economies. It is therefore considered plausible that conventional dependence relations may break down at extremes. Thus, from the inception of modern macroeconomics to the present, it has been acknowledged and discussed that nonlinear dependence in macro variables presents an important academic and policy issue. However, that discussion has a gap: it generally stops short of examining multivariate $(n>2)$ dependence, asymmetric dependence, and the practical difficulty of estimating nonlinear dependence on empirical data. The use of copulas is one way to fill this gap.

The research of Embrechts, McNeil, and Straumann (2002) introduces copulas into economics. The authors first show that standard Pearson correlations can go dangerously wrong as an investment signal. They then suggest the copula function as a flexible alternative to correlation, which can capture dependence throughout the entire distribution of economic variables. A copula $C$ is by definition a joint distribution with uniform marginals. In the bivariate case, that means

$$
C(u, v)=\operatorname{Pr}[U \leq u, V \leq v],
$$

\footnotetext{
${ }^{19}$ See Samuelson (1967); Brumelle (1974); Granger (2001); Hamilton (2001); Embrechts, McNeil, and Frey (2005), and Ibragimov (2009).

${ }^{20}$ For more details, see Keynes (1936), and Romer (2001), Chapter 5.
} 
where $U$ and $V$ are uniformly distributed 21

The intuition behind copulas is that they "couple" or join marginals into a joint distribution. Copulas often have convenient parametric forms, and summarize the dependence structure between variables 22 Specifically, for any joint distribution $F_{X, Y}(x, y)$ with marginals $F_{X}(x)$ and $F_{Y}(y)$, we can write the distribution as

$$
F_{X, Y}(x, y)=C\left(F_{X}(x), F_{Y}(y)\right)
$$

The usefulness of (2) is that we can simplify analysis of dependence in a distribution $F_{X, Y}(x, y)$ by studying instead a copula $C$. Since copulas characterize arbitrary joint distributions, in principle they allow us to examine the possibility of nonlinear dependence for important macroeconomic relations, following the logic of Keynes (1936), Keynes (1939), Granger (2001), and Phelps (2007).

We now proceed to discuss related literature, in roughly chronological order. Two important macro variables are consumption and investment. Positive dependence between consumption and national income is suggested by work on the consumption function, such as Friedman (1957) and Ando and Modigliani (1963) 23 Empirically, the US economy has positive average dependence between consumption and GDP 24 Regarding investment, the US economy exhibits positive average dependence between investment and output, as documented by Kydland and Prescott (1982) 25 A central macroeconomic dependence relation concerns the Phillips curve, the joint distribution between inflation and unemployment. Phillips (1958) documents negative dependence between unemployment rates and changes in wages in the UK. He argues that it supports the hypothesis that in general (except for extreme events when import prices rise enough to start a wage-price spiral), levels and

\footnotetext{
${ }^{21}$ See de la Peña, Ibragimov, and Sharakhmetov (2006), Definition 3.1. It is typical to express the copula in terms of the marginal distributions $F_{X}(x)$ and $F_{Y}(y)$. In general, the transformations from $X$ and $Y$ to their distributions $F_{X}$ and $F_{Y}$ are known as probability integral transforms, and $F_{X}$ and $F_{Y}$ can be shown to be uniformly distributed. See Cherubini, Luciano, and Vecchiato (2004), page 52; and Embrechts (2009).

${ }^{22}$ This result holds for multivariate $(n>2)$ quantities. It is due to Sklar (1959), who proves that copulas uniquely characterize continuous distributions. For non-continuous distributions, the copula will not necessarily be unique. In such situations, the empirical copula approach of Deheuvels (1979) helps narrow down admissible copulas.

${ }^{23}$ Strictly speaking, the dependence between consumption and output involves expectation of permanent income. There is a large body of research on dynamic consumption effects, such as Hall (1988).

${ }^{24}$ See Kydland and Prescott (1982), Table IV.

${ }^{25}$ See Kydland and Prescott (1982), Table IV.
} 
changes in unemployment explain the change in wages. The equation he estimates is of the form

$$
\log y=\alpha+b \log x
$$

where $y$ is the rate of change of wages and $x$ denotes percentage unemployment 26 The author estimates $b=-1.394$, thereby documenting a negative relation. Since the log function is convex, the dependence structure differs at the center versus the extremes. This finding was later extended to inflation and unemployment and named the Phillips curve. The dependence structure in the Phillips curve has strong policy implications, as shown in the following three cases. First, if the Phillips curve has equal tail dependence, then economic policy has equal effects during upturns and downturns 27 This outcome is consistent with stagflation. Second, if tail dependence is zero, then economic policy does not matter during extreme periods. Finally, an asymmetric Phillips curve means that negative shocks to aggregate demand will lower inflation more than positive shocks raise it. In related research, Laxton, Rose, and Tambakis (1999) show that standard empirical techniques are not powerful enough to identify convexity of the Phillips curve. In addition, Hamilton (2001) demonstrates that accounting for nonlinear dependence is important to identify the Phillips curve. Thus, empirically, nonlinearity is key in this macroeconomic relation 28 Such nonlinearity also has theoretical content. Phelps (1968) develops a theoretical model for the Phillips curve, based on a labor market with frictions, imperfect information, and adaptive expectations. He shows that if there are money-wage rigidities the observed Phillips curve will occur for large unemployment rates 29 However, for very small unemployment levels, the dependence structure will diverge, in the context of a disequilibrium wage-price spiral. Phelps' theoretical results therefore suggest asymmetric dependence 30

Lucas and Rapping (1969) develop a theoretical model of aggregate labor supply, again with adaptive expectations, and derive an unemployment function,

$$
U_{t}=\alpha+\beta_{1} \ln \frac{w_{t}}{w_{t-1}}+\beta_{2} \ln \frac{P_{t}}{P_{t-1}}+\beta_{3} U_{3} t+\epsilon_{t},
$$

\footnotetext{
${ }^{26}$ See Phillips (1958), page 290.

${ }^{27}$ Tail dependence denotes dependence of economic variables during extreme periods. See Section 3.

${ }^{28}$ More generally, Granger (2001) suggests that nonlinearity in macroeconomic variables is subtle, and not detectable without robust techniques. See also Rothman, van Dijk, and Franses (2001).

${ }^{29}$ See Phelps (1968), equation (33).

${ }^{30}$ A testable implication of the Phelps (1968) result is therefore examining whether right tail dependence or left tail dependence is more pronounced for inflation-unemployment. To the of our knowledge this type of test has not been conducted before.
} 
and find that $\beta_{1}$ and $\beta_{2}$ are negative 31 This is empirically upheld using US data from 1930 to 1965 . Thus, there is negative dependence between unemployment, wage growth, and inflation. Lucas (1972) analyzes the positive dependence between inflation and real GDP, which he considers to be "a central feature of the modern business cycle" $32 \mathrm{He}$ constructs a rational expectations, overlapping generations economy where money is neutral, and delivers the empirically observed positive dependence. This positive dependence arises as part of the solution to the general equilibrium framework, even though agents do not have money illusion. Lucas (1973) examines aggregate macroeconomic data from eighteen countries from 1951-1967. He documents mixed evidence of dependence between inflation and output, and stronger evidence for countries with stable prices, such as the US economy. Lucas (1975) constructs an equilibrium, rational expectations economy with imperfect information, that accounts for business cycles. The author finds that the following variables exhibit positive dependence with GDP: prices, investment shares and nominal interest rates. Lucas (1977) builds an equilibrium model to account for much of the dependence between prices and other variables in the macroeconomy. Kydland and Prescott (1982) develop an aggregative model with adjustment lags in production to explain dependence between output and other economic variables. Long and Plosser (1983) construct a frictionless rational expectations equilibrium model of the business cycle. Their model reproduces positive dependence across economic sectors, in accordance with empirical patterns of business cycles. King and Plosser (1984) extend the Lucas (1977) model to include monetary and banking considerations. They analyze a rational equilibrium model, where exchange in the real economy is enhanced via transaction services from the financial industry. The solution to their model delivers zero dependence between money and output growth, and positive dependence between money and prices 33 Hansen (1985) constructs an equilibrium macroeconomic model based on indivisible labor, where all fluctuations are due to variation in hours worked. The author documents that for quarterly series from 1955 to 1984 in the US economy, consumption, investment and labor supply are positively dependent with output 34 The solution to his model replicates much of this dependence pattern better than a standard model with divisible labor. Veldkamp and Van Nieuwerburgh (2006) analyze the fact that business cycles are asymmetric-downturns are typically short

\footnotetext{
${ }^{31}$ Lucas and Rapping (1969), equation (32).

${ }^{32}$ Lucas (1972), page 103.

${ }^{33}$ Also, King and Plosser (1984), page 372, show that prices and output are negatively dependent. Unlike our work, the authors' work concerns money growth and output growth, not levels.

${ }^{34}$ See Hansen (1985), Table 1. Hansen detrends his variables using the Hodrick and Prescott (1997) filter, as we do.
} 
while upturns are smooth and gradual. The authors construct an equilibrium model where agents take time to learn about aggregate productivity, since it is imperfectly observed. They document for US macro data from 1952 to 2002, positive dependence between output and variables such as investment, employment, and consumption. Their model is able to replicate much of the observed dependence. In similar vein, Veldkamp and Wolfers (2007) analyze a model of information acquisition where spatially-separated agents interact via their labor market choices and levels of aggregate information. The model's results are consistent with the observed pattern of industry dependence over the business cycle.

The above approaches analyze individual markets, and say little about systemic risk. Evidently household decisions, in aggregate, may have an externality effect on financial and economic markets. The existence of such externalities has been emphasized by several recent papers. We discuss the following article, since the results focus on distributional dependence 35 Ibragimov, Jaffee, and Walden (2009b) develop a model of catastrophic risks. They characterize the existence of non-diversification traps: situations where insurance providers may not insure catastrophic risks nor participate in reinsurance even though there is a large enough market for complete risk sharing. Conditions for this market failure to occur comprise limited liability or heavy left-tailedness of risk distributions, as described in Background Result 8 below 36 The authors prove that, in general nondiversification traps can arise only with distributions that have moderately heavy left tails, that is, asymmetric dependence. We summarize the preceding literature on macroeconomic dependence in eight stylized facts and theoretical results, below.

Background Result 1: Liquidity trap (Keynes (1936)). During normal times we should observe negative dependence between output and prices. During extreme times, there may be a liquidity trap, with asymmetric dependence between output and prices.

\section{Background Result 2: Dependence between output and labor markets.(Solon, Barsky,} and Parker (1994).) Empirically, employment and real wages exhibit positive average dependence with output in the US economy 37

\footnotetext{
${ }^{35}$ Other papers include Caballero and Krishnamurthy (2008); Krishnamurthy (2009); Shin (2009); and Danielsson, Shin, and Zigrand (2009).

${ }^{36}$ Economically speaking, if assets have infinite second moments, this represents potentially unbounded downside risk and upside gain. In the face of this, insurers prefer to ration insurance rather than decide coverage unilaterally. This parallels the credit rationing literature of Jaffee and Russell (1976) and Stiglitz and Weiss (1981).

${ }^{37}$ See also Phillips (1958); and Romer (2001), Chapter 4, where he uses the term procyclical to indicate dependence.
} 
Background Result 3: Money neutrality. (Phelps (1968), and Lucas (1972)). In a standard neoclassical macro model, monetary disturbances have zero dependence with real variables. In a Keynesian model, money may have positive dependence with employment and output 38

Background Result 4: Dependence in Inflation and GDP. (Lucas (1972)) In a rational expectations equilibrium, overlapping generations model with fully anticipated proportional money supply changes, there is positive dependence between inflation and real GDP 39

Background Result 5: Correlation complexity in Inflation and Unemployment. (Phelps (1968)). In an adaptive-expectations model, there is negative linear dependence between unemployment and inflation. However, dependence at the right extremes of unemployment should be high, while dependence at the left extremes should be small or variable.

Background Result 6: Dependence of Consumption and GDP. (Friedman (1957); Ando and Modigliani (1963); Kydland and Prescott (1982)). In a static aggregate non-rational expectations macro model, there is positive dependence between Consumption and GDP. Empirically in the US economy, there is evidence of positive linear dependence between consumption and real output.

Background Result 7: Dependence of Investment and GDP. (Kydland and Prescott (1982).) Empirically in the US economy there is positive linear dependence between investment and GDP.

Background Result 8, Nondiversification traps. Ibragimov, Jaffee, and Walden (2009b). Suppose insurers' liability is finite, the risks $X$ have $E(X)=0$, and $E\left(X^{2}\right)=\infty$. Then a nondiversification trap may occur. This result continues to hold for distributions with moderately heavy left tails. 40

\footnotetext{
${ }^{38}$ See also Romer (2001), Chapters 5 and 6.

${ }^{39}$ This result restates Theorem 4 in Lucas (1972).

${ }^{40}$ The term nondiversification trap denotes situations where insurance companies do not provide insurance, even though the market is large enough for complete risk sharing. Background Result 8 is a partial converse that we derive from part iii) of the authors' Proposition 6.
} 


\subsection{Consequences of measuring economic dependence by correlation}

Most of the above results are originally formulated with some variant of covariance. However, if we wish to isolate asymmetric dependence, covariances and correlations are not enough. In the next section, we will explain why correlation is misleading as a signal of systemic downturns. We also explain how copulas can help in estimating extreme dependence, since they are rank based and invariant to common economic transformations 41

Covariance measures average linear dependence 42 However, average dependence differs from dependence of the distribution, in general. For example, consider two variables $X$ and $Y . X$ is zero-mean and non-skewed: $E[X]=\bar{X}=0$ and $E\left[X^{3}\right]=0$. Furthermore, $Y$ satisfies a simple nonlinear relation with $X$, namely $Y=X^{2}$. Then the covariance between $X$ and $Y$ is

$$
\begin{aligned}
\operatorname{cov}(X, Y) & =E[(X-\bar{X})(Y-\bar{Y})] \\
& =E\left[(X-0)\left(X^{2}-\bar{Y}\right)\right] \\
& =E\left[X^{3}-X \bar{Y}\right] \\
& =E\left[X^{3}\right]-\bar{Y} E[X] \\
& =0 .
\end{aligned}
$$

Evidently $X$ and $Y$ have a perfect deterministic relation, but covariance cannot account for it. The reason is that covariance captures only linear and not distributional dependence 43 Thus, covariance cannot detect dependence in even the simplest continuous nonlinear relation, $Y=X^{2}$. Similar reasoning applies to any statistical measure that builds on correlation, such as linear regression 44 Such fragility of correlation is of practical importance in economic research and policy. From a research perspective, linear approximations are attractive for parsimony. However, the linear approach can mask theoretically important nonlinearities, as demonstrated by Granger (2001), Hamilton (2001), and Mogstad and

\footnotetext{
${ }^{41}$ Such research has already been used successfully in fields outside of macroeconomics, such as international economics, and banking and finance. See Okimoto (2008); Ane and Kharoubi (2001); Rosenberg and Schuermann (2006); and Patton (2006).

${ }^{42}$ See Embrechts, McNeil, and Straumann (2002).

${ }^{43}$ For further details on linearity of correlation, see Casella and Berger (1990), Chapter 4.

${ }^{44}$ Further drawbacks of correlation include non-invariance and volatility bias, as outlined in Section 3.
} 
Wiswall (2009). From a policy perspective, it is crucial to understand the dependence patterns of key macroeconomic variables during upturns versus downturns 45

\subsection{Relation of background results to copulas}

The research above emphasizes on theoretical and empirical grounds the importance of isolating dependence in the joint distribution of economic variables, in order to say something concrete about national economic performance. Most of the Background Results can be directly examined empirically using copulas since, as shown in (2), copulas characterize dependence 46 The only exception is Background Result 8, which is phrased in terms of the distributions, not copulas directly 47 We therefore summarize empirical implications of Background Result 8 in the following observation.

Observation 1, correlation complexity and asymmetric dependence. If the copula-based dependence and correlation estimates disagree, or if the copulas exhibit asymmetric dependence, then the set of economic variables may be prone to nondiversification traps. That is, individual rationality can lead to systemic risk.

\subsection{Related empirical research on asymmetric dependence}

Previous research on asymmetric dependence has tended to be in international economics or banking and finance. The approaches generally fall into either correlation or copula frameworks 48 The literature in each area is vast and growing, so we summarize only some

\footnotetext{
${ }^{45}$ For related literature on business cycle asymmetries, see De Long and Summers (1986); and Veldkamp and Van Nieuwerburgh (2006).

${ }^{46}$ It is possible to estimate the full joint distributions directly, but this leads to a problem of misspecification in both the marginals and dependence. Using copulas with standardized empirical marginals removes the problem of misspecification in the marginals. Therefore the only misspecification relates to dependence, which can be ameliorated with goodness of fit tests for copulas of different shapes. For further background on issues related to choosing copulas, see Chen and Fan (2006), Cherubini, Luciano, and Vecchiato (2004), Embrechts (2009), Joe (1997), Mikosch (2006), and Nelsen (1998).

${ }^{47}$ Therefore, for Background Result 8, copulas can at best show that the dependence in the data satisfies a necessary condition. For example, if the estimated copulas exhibit tail dependence, then it is possible for nondiversification traps to occur. There is no general link between copulas for heavy-tailed distributions in terms of other classes of copulas. Thus, Observation 1 merely summarizes necessary conditions that dependence must satisfy in order to obtain non-diversification as discussed above. We are grateful to Laurens de Haan and Thomas Mikosch for clarifying this issue.

${ }^{48}$ There is also a related literature that examines dependence using extreme value theory, threshold correlations, and dynamic skewness. These papers generally find evidence of nonlinear, asymmetric dependence.
} 
key contributions 49 With regard to correlation, a major finding of Longin and Solnik (1995) and Ang and Bekaert (2002) is that international stock correlations tend to increase over time. Moreover, Cappiello, Engle, and Sheppard (2006) document that international stock and bond correlations increase in response to negative returns, although part of this apparent increase may be due to an inherent volatility-induced bias 50 Regarding copula-based studies of dependence, an early paper by Mashal and Zeevi (2002) shows that the dependence structures of equity returns, currencies and commodities exhibit joint heavy tails. Patton (2004) uses a conditional form of the copula relation (2) to examine dependence between small and large-cap US stocks. He finds evidence of asymmetric dependence in the stock returns. Patton (2004) also documents that knowledge of this asymmetry leads to significant gains for investors who do not face short sales constraints. Patton (2006) uses a conditional copula to assess the structure of dependence in foreign exchange. Using a sample of Deutschemark and Yen series, Patton (2006) finds strong evidence of asymmetric dependence in exchange rates. Jondeau and Rockinger (2006) successfully utilize a model of returns that incorporates a skewed-t GARCH for the marginals, along with a dynamic gaussian and student-t copula for the dependence structure. Rosenberg and Schuermann (2006) analyze the distribution of bank losses using copulas to represent, very effectively, the aggregate expected loss from combining market risk, credit risk, and operational risk. Rodriguez (2007) constructs a copula-based model for Latin American and East Asian countries. His model allows for regime switches, and yields enhanced predictive power for international financial contagion. Okimoto (2008) also uses a copula model with regime switching, focusing on the US and UK. Okimoto (2008) finds evidence of asymmetric dependence between stock indices from these countries. Harvey and de Rossi (2009) construct a model of time-varying quantiles, which allow them to focus on the expectation of different parts of the distribution. This model is also general enough to accommodate irregularly spaced data. Harvey and Busetti (2009) devise tests for constancy of copulas. They apply these tests to Korean and Thai stock returns and document that the dependence structure may vary over time. Ning (2006) analyzes the dependence between stock markets and foreign exchange, and discovers significant upper and lower tail dependence between

For extreme value approaches, see Longin and Solnik (2001), Hartmann, Straetmans, and de Vries (2003), and Poon, Rockinger, and Tawn (2004). For threshold correlations, see Ang and Chen (2002). For dynamic skewness, see Harvey and Siddique (1999).

${ }^{49}$ For summaries of copula literature, see Cherubini, Luciano, and Vecchiato (2004), Embrechts, McNeil, and Frey (2005), Jondeau, Poon, and Rockinger (2007), and Patton (2009). For more general information on dependence in economics, see Embrechts, Kluppelberg, and Mikosch (1997), and Cherubini, Luciano, and Vecchiato (2004).

${ }^{50}$ See Forbes and Rigobon (2002). 
these two asset classes. Ning (2008) examines the dependence of stock returns from North America and East Asia. She finds asymmetric, dynamic tail dependence in many countries. Ning (2008) also documents that dependence is higher intra-continent relative to across continents. Chollete, Heinen, and Valdesogo (2009) use general canonical vines in order to model relatively large portfolios of international stock returns from the G5 and Latin America. They find that the model outperforms dynamic gaussian and student-t copulas, and also does well at modifying the VaR for these international stock returns. These papers all contribute to the mounting evidence on significant asymmetric dependence in financial and economic variables.

\subsection{Contribution of our paper}

Our paper contributes to the literature in several important ways. First, we examine macroeconomic dependence using both correlation and nonlinear copula approaches, and are agnostic ex ante about which technique is appropriate. Our paper appears to be the first to analyze national dependence using both methods 51 Second, our paper establishes new stylized facts about macroeconomic dependence during extreme periods. These results may be important in defining business cycles. Previous macroeconomic research focuses very justifiably on establishing the existence of average dependence (correlations or regression). This is understandable, since an important first step is to document whether dependence exists, on average. Third, unlike other papers on dependence, our paper builds on specific economic theories of macroeconomic dependence to study a particular national economy. Previous empirical research on dependence attempts to document, atheoretically, if there is extreme or asymmetric dependence for particular markets. Understandably, these empirical studies are generally motivated by implications for individual market participants and risk management. By contrast, our paper examines broader macroeconomic variables to test for joint downturns and upturns. Our results are therefore relevant for informing policy regarding bubbles and crashes. Finally, we discuss systemic implications of the economy's dependence structure. Such considerations are absent from previous empirical research in both nonlinear econometrics and macroeconomics.

We position our paper transparently in terms of what our methodology can and cannot do. In particular, in Observation 1, we make it clear that the copula approach in some cases

\footnotetext{
${ }^{51}$ We assume time-invariant dependence in this study. While a natural next step is time-varying conditional dependence, we start at the unconditional case, since there has been no comparative research even at this level.
} 
allows us to assess only necessary conditions about economic dependence. Finally, to the best of our knowledge, this paper is the first to use robust rank-based methods to analyze dependence of important investment and policy variables in the US economy.

\section{Measuring dependence in the macroeconomy}

Dependence is assessed with various measures. If two economic variables have relatively low dependence, they offer a better protection from systemic downturns than otherwise. In light of the above discussion, we estimate dependence in two ways, using correlations and copulas 52 The extent of discrepancy between the two can suggest correlation complexity. It can also be informative if we wish to obtain a sense of possible mistakes from using correlations alone. We now define the dependence measures. Throughout, we consider $X$ and $Y$ to be two random variables, with a joint distribution $F_{X, Y}(x, y)$, and marginals $F_{X}(x)$ and $F_{Y}(y)$, respectively.

\subsection{Correlations}

Correlations are the most familiar measures of dependence in economics. If properly specified, correlations tell us about average dependence over the entire distribution. The Pearson correlation coefficient $\rho$ is the covariance divided by the product of the standard deviations:

$$
\rho=\frac{\operatorname{Cov}(X, Y)}{\sqrt{\operatorname{Var}(X) \cdot \operatorname{Var}(Y)}} .
$$

The main advantage of correlation is its tractability. There are, however, a number of theoretical shortcomings, especially in economic settings 53 First, a major shortcoming is that correlation is not invariant to monotonic nonlinear transformations. Thus, the correlation of two economic series may differ from the correlation of the squared or log series. Second, there is evidence of infinite variance in economic data 54 From equation (3), if either $X$ or $Y$ has infinite variance, the estimated correlation may give little information on dependence, since it will be undefined or close to zero. A third drawback concerns estimation bias:

\footnotetext{
${ }^{52}$ Readers already familiar with dependence and copula concepts may proceed to Section 4.

${ }^{53}$ Disadvantages of correlation are discussed by Embrechts, McNeil, and Straumann (2002).

${ }^{54}$ See Mandelbrot (1963); Fama (1965); Gabaix, Gopikrishnan, Plerou, and Stanley (2003); and Rachev (2003).
} 
by definition the conditional correlation is biased and spuriously increases during volatile periods 55 Fourth, correlation is a linear measure and therefore may overlook important nonlinear dependence. It does not distinguish, for example, between dependence during up and down markets 56 Whether these shortcomings matter in practice is an empirical question that we address in this paper.

As an example of the shortcomings of using correlation, recall that consumption is positively related to income, according to the permanent income and life cycle hypotheses 57 This relation is often tested using a regression of current consumption $C_{i}$ on the appropriate income measure $Y$,

$$
C_{i}=a+\beta Y_{i}+\epsilon_{i}
$$

Since $\beta=\frac{\operatorname{Cov}(Y, C)}{\operatorname{Var}(Y)}$, then $\beta$ is biased toward 0 during periods of big changes in $\mathrm{Y} 58$ Moreover, as demonstrated in section 2.1, correlations will fail to detect even basic nonlinear dependence.

A nonlinear correlation measure is the rank (or Spearman) correlation, $\rho_{S}$. This is more robust than the traditional correlation. $\rho_{S}$ measures dependence of the ranks, and can be expressed as $\rho_{S}=\frac{\operatorname{Cov}\left(F_{X}(x), F_{Y}(y)\right)}{\sqrt{\operatorname{Var}\left(F_{X}(x)\right) \operatorname{Var}\left(F_{Y}(y)\right)}} 59$ The rank correlation is especially useful when analyzing data with a number of extreme observations, since it is independent of the levels of the variables, and therefore robust to outliers. A related measure is Kendall's tau, $\tau$, which measures the difference between positive and negative dependence: $\tau(X, Y)=$ $P[(X-\tilde{X})(Y-\tilde{Y})>0]-P[(X-\tilde{X})(Y-\tilde{Y})<0]$, where the tildes denote independent copies of the relevant random variable. Another nonlinear correlation measure is one we term downside risk $60 d(u)$. This function measures the conditional probability of

\footnotetext{
${ }^{55}$ See Forbes and Rigobon (2002). After adjusting for such bias, Forbes and Rigobon (2002) document that prior findings of international dependence (contagion) are reversed.

${ }^{56}$ Such nonlinearity may be substantial, as illustrated by Ang and Chen (2002). These researchers document significant asymmetry in downside and upside correlations of US stock returns.

${ }^{57}$ See Romer (2001), Chapter 7.

${ }^{58}$ Furthermore, correlations are biased during periods of high volatility, see Forbes and Rigobon (2002).

${ }^{59}$ See Cherubini, Luciano, and Vecchiato (2004), page 100.

${ }^{60}$ The concept of downside risk appears in a number of settings without being explicitly named. It is the basis for many measures of systemic risk, see Cherubini, Luciano, and Vecchiato (2004) page 43; Hartmann, Straetmans, and de Vries (2003); and Adrian and Brunnermeier (2008).
} 
an extreme event beyond some threshold $u$. For simplicity, normalize variables to the unit interval $[0,1]$. Hence

$$
d(u) \equiv \operatorname{Pr}\left(F_{X}(x) \leq u \mid F_{Y}(y) \leq u\right)
$$

The final nonlinear correlation measures are left and right tail dependence, $\lambda_{l}(u)$ and $\lambda_{r}(u) . \lambda_{l}(u)$ is the limit of downside risk $d(u)$, while $\lambda_{r}(u)$ is the limit of upside gains.

$$
\begin{aligned}
& \lambda_{l}(u) \equiv \lim _{u \downarrow 0} \operatorname{Pr}\left(F_{X}(x) \leq u \mid F_{Y}(y) \leq u\right) . \\
& \lambda_{r}(u) \equiv \lim _{u \uparrow 1} \operatorname{Pr}\left(F_{X}(x) \geq u \mid F_{Y}(y) \geq u\right) .
\end{aligned}
$$

Tail dependence is important because it measures the asymptotic likelihood that two variables go down or up at the same time. Economic examples include the liquidity trap of Keynes (1936) and the nonlinear Phillips curve of Phelps (1968), presented in Background Results 1 and 5 above.

\subsection{Copulas}

If we knew the entire joint distribution of macroeconomic variables, we could summarize all relevant dependence and therefore all potential for systemic downturns. In a collection of two economic variables $X$ and $Y$, all dependence is contained in the joint density $f_{X, Y}(x, y)$. This information is often not available, especially for large economic systems, because there might be no simple parametric joint density that characterizes the relationship across all variables. Moreover, there is a great deal of estimation and mis-specification error in attempting to find the density parametrically.

An alternative to measuring dependence in this setting is the copula function $C(u, v)$. From expression (1) above, a copula is a joint distribution with uniform marginals $U$ and $V, C(u, v)=\operatorname{Pr}[U \leq u, V \leq v]$. As shown in (2), any joint distribution $F_{X, Y}(x, y)$ with continuous marginals is characterized by a copula distribution $C$ such that $F_{X, Y}(x, y)=$ $C\left(F_{X}(x), F_{Y}(y)\right)$. It is often convenient to differentiate equation (2) and use a corresponding "canonical" density version

$$
f(x, y)=c\left(F_{X}(x), F_{Y}(y)\right) \cdot f_{X}(x) \cdot f_{Y}(y),
$$


where $f(x, y)$ and $c\left(F_{X}, F_{Y}\right)$ are the joint and copula densities, respectively 61 Equation (8) is interesting because it empowers us to separate out the joint distribution from the marginals. For example, if we are interested in why heavy tailedness increases likelihood of a joint downturn in employment and GDP, this could come from either the fact that the marginals are heavy-tailed, or their dependence is heavy-tailed, or both. This distinction is relevant whenever we are interested in the downside tendencies of the entire economy, more than the heavy-tailedness of each macroeconomic variable in the economy.

There are a number of parametric copula specifications 62 These copulas have different types of dependence: symmetric, asymmetric, and extreme dependence. A general copula that allows for both symmetric and asymmetric dependence between macro variables, is the Symmetrised Joe Clayton (SJC) copula used in Patton (2006). The SJC copula is defined as

$$
C_{S J C}\left(u, v \mid \lambda r, \lambda_{l}\right)=0.5 \times\left(C_{J C}\left(u, v \mid \lambda_{r}, \lambda_{l}\right)+C_{J C}\left(1-u, 1-v \mid \lambda_{l}, \lambda_{r}\right)+u+v-1\right),
$$

where $C_{J C}\left(u, v \mid \lambda_{r}, \lambda_{l}\right)$ is the Joe-Clayton copula. The Joe-Clayton copula is in turn defined as

$$
C_{J C}\left(u, v \mid \lambda_{r}, \lambda_{l}\right)=1-\left(1-\left\{\left[1-(1-u)^{k}\right]^{-r}+\left[1-(1-v)^{k}\right]^{-r}-1\right\}^{-1 / r}\right)^{1 / k}
$$

where $k=1 / \log _{2}\left(2-\lambda_{r}\right)$ and $r=-1 / \log _{2}\left(\lambda_{l}\right)$, and $\lambda_{l}$ and $\lambda_{r} \in(0,1)$. By construction, the SJC copula is symmetric when $\lambda_{l}=\lambda r$. This copula is very flexible since it allows for both asymmetric upper and lower tail dependence, with symmetric dependence as a special case.

There are several main advantages of using copulas in macroeconomics. First, they are a convenient choice for modeling potentially nonlinear dependence of economic variables, such as systemic downturns and correlated defaults. This aspect of copulas is especially attractive since they nest some important forms of dependence, as described in Section 3.3. A second advantage is that copulas can aggregate systemic risk from disparate sources, such as credit and operational risk in a banking sector. This is possible even for risk distributions that are subjective and objective, as in Rosenberg and Schuermann (2006). In a

\footnotetext{
${ }^{61}$ Specifically, $f(x, y)=\frac{\partial^{2} F_{X, Y}(x, y)}{\partial x \partial y}$, and similarly $c\left(F_{X}(x), F_{Y}(y)\right)=\frac{\partial^{2} C\left(F_{X}(x), F_{Y}(y)\right)}{\partial x \partial y}$. The terms $f_{X}(x)$ and $f_{Y}(y)$ are the marginal densities.

${ }^{62}$ See Joe (1997); Nelsen (1998); and Embrechts, McNeil, and Frey (2005) for various figures and functional forms of copulas.
} 
related sense, copulas permit one to model joint dependence in an economic system without specifying the distribution of individual variables in the system 63 A third advantage is invariance. Since the copula is based on ranks, it is invariant under strictly increasing transforms. That is, the copula extracts the way in which $x$ and $y$ comove, regardless of the scale used to measure them 64 Fourth, since copulas are rank-based and can incorporate asymmetry, they are also natural dependence measures from a theoretical perspective. The reason is that a growing body of research recognizes that economic agents care a great deal about the ranks and downside performance of their economic decisions 65 There are two drawbacks to using copulas. First, from an economic perspective, a potential disadvantage is that many copulas do not have moments that are directly related to Pearson correlation. It may therefore be difficult to compare copula results to those of macroeconomic models based on correlations or variances. This is not a big issue for our study, since we also report and discuss rank-based correlations and Kendall's tau. Second, from a statistical perspective, it is not easy to say which parametric copula best fits the data, since some copulas may fit better near the center and others near the tails. This issue is not strongly relevant to our paper, since the most important theoretical background research from Section 2 focuses on asymmetry and tail dependence. Thus the emphasis is on the shape of copulas, rather than on a specific copula. Further, we use several specification checks, namely AIC and BIC.

More broadly, since copulas are joint distributions, they are naturally well-suited to discussions of a vast array of research and policy issues in economics. In particular, copulas are directly relevant to macroeconomics in the context of central bank policy 66 In an increasingly globalized economy, markets exhibit unexpectedly greater dependence during certain periods, as evidenced by the recent international contagion episodes and US mortgage market spillovers. Copulas inherently capture such complex dependence structures.

\footnotetext{
${ }^{63}$ This is usually expressed by saying that copulas do not constrain the choice of individual or marginal asset distributions. For example, if we model unemployment and inflation as bivariate normal, this automatically restricts both the individual (marginal) unemployment and inflation to be univariate normal. Our semi-parametric approach avoids restricting the marginals by using empirical marginal distributions, based on ranks of the data. Specifically, first the data for each marginal are ranked to form empirical distributions. These distributions are then used in estimating the parametric copula.

${ }^{64}$ See Schweizer and Wolff (1981). For more details on copula properties, see Nelsen (1998), Chapter 2.

${ }^{65}$ See Kahneman and Tversky (1979); Benartzi and Thaler (1995); Barberis, Huang, and Santos (2001); and Polkovnichenko (2005).

${ }^{66}$ Other issues include optimal commodity bundling, income inequality, expected utility and parsimonious modelling of dependent multivariate time series. For research on some of these disparate topics, see the work of Embrechts, McNeil, and Frey (2005); Patton (2006); and Ibragimov (2009).
} 


\subsection{Relationship of dependence measures}

We briefly outline the relationship of the dependence measures 67 If the true joint distribution is bivariate normal, then the copula and traditional correlation give the same information. Once we move far away from normality, there is no clear relation between correlation and the other measures. However, all the other, more robust measures of dependence are pure copula properties, and do not depend on the marginals. We describe relationships for rank correlation $\rho_{S}$, downside risk $d(u)$, and tail dependence $\lambda(u)$ in turn. The relations between copulas, rank correlation and Kendall's $\tau$ are given by

$$
\rho_{S}=12 \int_{0}^{1} \int_{0}^{1} C(u, v) d C(u, v)-3
$$

and

$$
\tau=4 \int_{0}^{1} \int_{0}^{1} C(u, v) d C(u, v)-1 .
$$

Thus, if we know the correct copula, we can recover rank correlation and Kendall's $\tau$, and vice versa. Therefore, rank correlation and Kendall's $\tau$ are pure copula properties. Regarding downside risk, it can be shown that $d(u)$ satisfies

$$
\begin{aligned}
d(u) & \equiv \operatorname{Pr}\left(F_{X}(x) \leq u \mid F_{Y}(y) \leq u\right) \\
& =\frac{\operatorname{Pr}\left(F_{X}(x) \leq u, F_{Y}(y) \leq u\right)}{\operatorname{Pr}\left(F_{Y}(y) \leq u\right)} \\
& =\frac{C(u, u)}{u},
\end{aligned}
$$

where the third line uses definition (11) and the fact since $F_{Y}(y)$ is uniform, $\operatorname{Pr}\left[F_{Y}(y) \leq\right.$ $u]=u$. Hence, downside risk is also a pure copula property and does not depend on the marginals at all. Since tail dependence $\lambda_{l}(u)$ is the limit of downside risk, it follows from (7) and (12) that $\lambda_{l}(u)=\lim _{u \downarrow 0} \frac{C(u, u)}{u}$. To summarize, the nonlinear measures are directly related to the copula, and $\rho$ and the normal copula give the same information when the data are jointly normal. While the above discussion describes how to link the various concepts in theory, there is little empirical work comparing the different dependence measures, which provides a further rationale for our empirical study.

\footnotetext{
${ }^{67}$ For proofs on the relations between dependence measures, see Cherubini, Luciano, and Vecchiato (2004) Chapter 3; Embrechts, McNeil, and Frey (2005); and Jondeau, Poon, and Rockinger (2007). Throughout, we assume continuous marginal distributions, as in Embrechts, McNeil, and Frey (2005), chapter 5.
} 


\section{Data and results}

The data that we use comprise both monthly and quarterly data from the Federal Reserve Bank of St. Louis 68 Monthly data are from January 1964 to December 2008, and include the following variables: the riskfree rate, price (measured in consumer price index, $\mathrm{CPI}$ ), inflation, employment rate, wage, consumption, money supply, and GDP. Inflation is computed as the log difference of the consumer price index (CPI) in the past twelve months. Quarterly data are from January 1964 to October 2008, and include investment in addition to all other variables in the monthly data. Quarterly data on wages, money supply, interest rate, consumer price index and employment rate are not available since the Federal Reserve is currently updating these series. Therefore we compute these by taking the average of three months' data. The macroeconomic variables, including GDP, wage, consumption and investment, are in real terms. GDP is not available at monthly frequency, so we use the Industrial Production Index as an approximation. Since all macro variables are nonstationary, we estimate the dependence of the log differences of all variables, which are stationary.

\subsection{Estimates of macroeconomic dependence: correlations}

We first examine Background results 1, 2, and 4 at normal times using linear and rank correlations. Table 1 displays correlations between GDP and other macro variables. Panel A shows monthly correlations. GDP has significant positive correlations with the interest rate, employment rate, real wages, and real consumption while it has negative correlation with the price level CPI. The positive correlation between GDP and interest rates is consistent with the Taylor (1993) rule, that the Fed would increase the Fed funds rate in order to control inflation within a targeting range if GDP increases. The negative correlation between GDP and prices is consistent with Background result 1 in normal times. Thus, using a linear dependence measure, a high price level is associated with poor economic performance and vice versa. On the other hand, the correlation between GDP and inflation is positive, which is consistent with the Background result 4 of Lucas (1972). The positive correlation between GDP and the employment rate and real wages is consistent with Background result 2. The rank correlations Spearman's rho and Kendall's tau have the same sign as the linear correlations and are strongly statistically significant as well. Thus our linear and

\footnotetext{
${ }^{68}$ Our motivation for the choice of variables is based on Section 2's discussion.
} 
rank correlation results of GDP and other macro variables agree with background results in normal, non-extreme situations. It is also important to consider the highest and lowest correlations. The highest linear correlation is between GDP and employment, at 0.3591. This is also true for the rank correlations, Spearman's rho and Kendall's tau, at 0.3461 and 0.2453 respectively. The smallest positive linear correlations are between GDP and real wages. There are some discrepencies between linear correlations and rank correlations. For example, the linear correlation between GDP and interest rate exceeds that between GDP and consumption. However, the rank correlations show the opposite order for these two sets of variables. Therefore, empirically linear and rank correlations do not always agree with each other.

Panel B displays results from quarterly data. Again, significant positive dependence is found in all except the GDP-Price pair, which has significant negative linear and rank correlations. The strength of dependence is generally stronger than in monthly data. For example, the linear, Spearman's rho and Kendall's tau correlations for the GDP-consumption pair increases from $0.2379,0.2427,0.1662$ in monthly data to $0.6690,0.5824,0.4253$ in quarterly data respectively. Further, the maximum dependence is now for GDP-consumption, instead of the pair GDP-employment as in monthly data.

Next, in Table 2, we examine the dependence between money supply and other macro variables, in order to investigate money neutrality of Background result 3. Panel A shows the monthly estimates. The linear correlation for the money-employment pair is insignificant, which is consistent with money neutrality. The rank correlations for this pair are also insignificant. For money and GDP, surprisingly, the linear correlation is significantly negative, which contradicts both money neutrality and the new Keynesian model. This result may be due to the inherent drawbacks of linear correlation. For example, linear correlation is only appropriate for measuring dependence in elliptical distributions, and these variables may not be elliptical 69 The rank correlations are statistically insignificant, consistent with money neutrality. Panel B presents results from the quarterly data, where all of the dependence measures are statistically insignificant. Therefore, our results indicate neutrality of money, that is, neither employment nor output is dependent with money supply. Moreover, in monthly data the linear and rank correlations disagree, indicating correlation complexity.

In Table 3 we present the dependence between inflation and other variables, related to Background results 4 and 5. In Panel A, the monthly data display significant positive dependence

\footnotetext{
${ }^{69}$ See Samuelson (1967); Chamberlain (1983); and Embrechts, McNeil, and Straumann (2002).
} 
for both inflation-employment and inflation-GDP. These results hold for both linear and rank correlations. Since employment is inversely related to unemployment, the positive dependence for inflation-employment implies a negative dependence for unemploymentGDP. These findings are consistent with Background results 4 and 5. Interestingly, if measured with linear correlation, dependence is larger for inflation-GDP than for inflationemployment. However, if measured in rank correlations, the degree of dependence is larger for inflation-employment than for inflation-GDP. Thus, empirically a greater linear correlation between two macro variables occurs with a relatively smaller rank correlation. This important discrepancy is also reflected in the quarterly results from Panel B. Specifically, we find significant positive linear correlations for inflation-GDP. However, in contrast to the linear correlations, the rank correlations are statistically insignificant. Such lack of conformity in dependence measures is further evidence of correlation complexity in the US macroeconomy.

Lastly, in Table 4, we present linear and rank correlations between investment and GDP 70 We find significant dependence in this pair, according to both linear and rank correlations. The highest dependence is the linear correlation, at 0.7883 . The lowest is the Kendall's rank correlation, at 0.5649 . Such strong dependence between GDP and investment is consistent with Background result 7.

\subsection{Estimates of macroeconomic dependence: copulas}

\subsubsection{Estimation method}

One advantage of copula approach is that it can separate the dependence structure from the marginals, with dependence completely captured in the copula function 71 Since our focus is on the dependence between macro variables, rather than their marginals, we specify a parametric copula function but make no assumptions on the marginal distributions of the macro variables. Therefore, the approach is free of specification errors for the marginals 72 The estimation procedure comprises two steps. In the first step, the marginal distribution

\footnotetext{
${ }^{70}$ Since investment data are only available quarterly, we are restricted to discussing quarterly results for this pair.

${ }^{71}$ See Sklar (1959); and Embrechts, McNeil, and Frey (2005); and Patton (2006).

${ }^{72}$ Our approach is therefore semi-parametric. For further details, see Joe (1997), and Cherubini, Luciano, and Vecchiato (2004). Statistical properties of this approach are highlighted in the simulation studies of Fermanian and Scaillet (2003).
} 
function $G($.$) is estimated non-parametrically via its rescaled empirical cumulative distri-$ bution function (ECDF)

$$
\widehat{F}\left(x_{t}\right)=\frac{1}{T+1} \sum_{t=1}^{T} 1\left\{X_{t}<x\right\} .
$$

The ECDF is rescaled to ensure that the first order condition of the copula's log-likelihood function is well defined for all finite $T 73$ By the Glivenko-Cantelli theorem, $\widehat{F}_{X}\left(x_{t}\right)$ converges to its theoretical counterpart $F\left(y_{t}\right)$ uniformly.

In the second step, given the non-parametrically estimated ECDF, $\left.\widehat{F\left(x_{t}\right.}\right)$ and $\widehat{G}\left(y_{t}\right)$, we estimate the copula parameters $\theta_{c}$ parametrically by maximum likelihood, with

$$
\begin{aligned}
\hat{\theta}_{c} & =\arg \max _{\theta_{c}} \widetilde{L}, \\
\text { where } \widetilde{L}\left(\theta_{c}\right) & =\frac{1}{T} \sum \log c\left(\widehat{F}\left(x_{t}\right), \widehat{G}\left(y_{t}\right) ; \theta_{c}\right),
\end{aligned}
$$

where $\mathrm{c}($.$) is the copula density function. Joe (1997) proves that under a set of regularity$ conditions, the two-step estimator is consistent and asymptotically normal. Joe (1997) also demonstrates that the two-step method is highly efficient. In addition, as indicated in Patton (2006), this method has the benefit of being computationally tractable. Chen and Fan (2006) establish asymptotic properties for this semi-parametric estimator. Copula estimation requires that the series be i.i.d. Since many of our macro series are not i.i.d., thus we filter the variables with various ARMA-GARCH models 74 We then compute the ECDFs of the filtered variables, which are used in the second-stage maximum likelihood estimation.

\subsubsection{Results}

We first discuss, in Table 5] Background results 1, 2, and 6 at extreme market situations. Panel A displays tail dependence estimates. First, we find that tail dependence in the GDPinterest rate pair is insignificant. This implies that, at extreme economic times, interest rates are not likely to decrease with GDP. Similarly, during economic booms, interest rates do not increase with GDP. This indicates an empirical deviation from the Taylor rule during extreme economic situations. In order to examine the liquidity trap, we examine tail de-

\footnotetext{
${ }^{73}$ See Genest, Ghoudi, and Rivest (1995), and Chen and Fan (2006) for further discussion on this methodology.

${ }^{74}$ Details of the filtering procedure for the macro variables are available from the authors, upon request.
} 
pendence in the GDP-negative interest rate pair. We need to examine negative interest rates because the liquidity trap hypothesis involves positive dependence between lower interest rates and higher GDP. The dependence parameter from the GDP-negative interest rate pair therefore allows us to see whether large decreases in interest rates are accompanied by large increases in GDP. If this were true, we would observe a significant positive right tail dependence between GDP and negative interest rates. However, we find that right tail dependence is 0 in the second column of Panel A of Table 5 Therefore, a huge decrease in interest rates does not occur together with an increase in GDP, implying silence of monetary policy. This result supports the liquidity trap in Background result 1. This observation is corroborated by zero tail dependence in the GDP-price pair. Second, there exists significant left and right tail dependence for the GDP-employment pair, with left tail dependence (0.1952) significantly higher than right tail dependence (0.1132). Hence, extremely low GDP and low employment rates tend to coincide during economic crises, while extremely high GDP and high employment rate are likely to occur together during economic booms. These tendencies are asymmetric, becase the GDP-employment pair is more likely to be extremely low during extreme economic downturn than to be jointly high during economic upturns. We find no tail dependence for the GDP-real wage pair. This result may reflect labor market rigidities. Thus at extremes, our results only partially support Background result 2, that employment and real wages have positive dependence with output. We now discuss Background result 6, positive dependence between consumption and GDP. We find significant dependence in both left and right tails. Again, there is strong asymmetry. Left tail dependence is 0.1864 , while right tail dependence is 0.0090 . Thus during economic downturns (upturns), low (high) GDP tends to coincide with low (high) consumption. This tendency is asymmetric, and more pronounced during economic downturns than upturns.

Panel B presents quarterly results. These generally agree with the monthly results, but with higher values and statistic significance 75 The main differences are as follows. First, the extreme dependence for the GDP-employment and GDP-consumption pairs are much stronger than those from monthly data. This reinforces the asymmetric dependence for the GDP-employment and GDP-consumption pairs. Second, there exists significant left tail dependence for the GDP-interest rate pair. This implies a possible policy ineffectiveness of the Fed's interest rate management, during economic downturns GDP falls significantly even when the interest rate is reduced heavily. This again supports the liquidity trap hy-

\footnotetext{
${ }^{75}$ The relatively greater tail dependence in quarterly data may be explained by the fact that monthly GDP data are not available. As mentioned above, they are approximated by the Industrial Production Index, which does not include all output.
} 
pothesis. From this perspective, the Taylor (1993) rule receives support even during an extreme economic downturn. Finally, left tail dependence for the GDP-real wage pair is significantly positive, indicating significant decreases in real wage during extreme economic downturns.

In light of the above discussion, we summarize our results as follows in the following four points. First, the Taylor rule appears to be followed in extreme economic downturns but not during upturns. Second, our results support the view of liquidity traps during extreme economic times. Third, during economic downturn when GDP drops, the employment rate, real wages, and real consumptions are likely to decrease as well. However, during economic upturns when GDP rises, employment and real consumption also tend to increase, but with relatively lower magnitude. Fourth, real wages tend not to increase with GDP during economic upturns.

Table 6 presents dependence between money, employment and GDP during extreme economic conditions. We find that both left and right tail dependence coefficients are statistically insignificant. Thus, money is neutral at extremes. This result is robust to both the monthly and quarterly data, and is consistent with our previous findings from linear and rank correlations.

In Table 7, we evaluate Background results 4 and 5, regarding dependence in inflationGDP at extremes, and correlation complexity in inflation-unemployment, respectively. In both monthly and quarterly results, inflation-GDP shows insignificant extreme dependence, which is different from the positive inflation-GDP dependence at equilibrium stated in Background result 4 . Thus the dependence under extreme economic situations differs from the dependence under normal economic situations for the inflation-GDP pair. Inflationemployment exhibits significant, positive left tail dependence, but no right tail dependence. Since employment is inversely related to unemployment, this is consistent with the Phelps (1968) conjecture that unemployment and inflation are asymmetrically dependent at extremes in Background result 5: dependence at the right (left) extremes of unemployment (employment) should be high, while dependence at the left (right) extremes of unemployment (employment) should be small. In quarterly data, although the dependence for inflation-employment is insignificant, the value of left tail dependence is 0.409 while right tail dependence is about 0 , which is again consistent with Background result 5 at extreme situations. 
Finally, in Table 8 we present extreme dependence between investment and GDP to evaluate the Background result 7 . We find significant left and right tail dependence between investment and GDP. The dependence is economically significant, with left and right tail dependence parameters at 0.5948 and 0.5756 respectively. A simple $t$ test of the null of symmetric tail dependence rejects the null, indicating asymmetric dependence 76 Thus, investment and GDP move together during extreme economic conditions, and are more dependent during economic downturns than upturns.

To summarize the extreme dependence results, our most striking finding is that GDP is asymmetrically related to employment, consumption, and investment, from Table 5 and Table 8. This indicates that during big downturns in economic activity, employment, consumption and investment fall, and do not rise as much during big upturns. From Table 5, we also find evidence of liquidity traps during economic downturns. From Table 6, we find evidence of money neutrality during extreme economic conditions. From Table 7, we observe that inflation is asymmetrically related to employment. That is, employment (unemployment) is dependent with inflation at the left (right) tail during economic downturns, but is not dependent with inflation at the right (left) tail during economic upturns.

\subsection{Comparing correlations and copulas}

In terms of comparison, both correlations and copulas show diversity in the dependence structure of the US macroeconomy. The two approaches agree that GDP is highly dependent with investment and employment. Both approaches also show evidence of money neutrality. However, they do not agree with each other on the dependence of many other pairs. For example, GDP is linearly dependent with the interest rate and price level, but not tail dependent with the price level. Inflation is linearly correlated with employment and GDP, but not tail dependent with the latter. The fact that copulas and correlations disagree, and the asymmetric dependence in some series, are consistent with the necessary conditions for systemic risk of Ibragimov, Jaffee, and Walden (2009a), as in Observation 1.

Our documentation of significant joint extremes suggests that the US economy is susceptible to episodes of simultaneous instability in two or more key macro variables. This result may be surprising in light of theoretical research which often assumes generic existence of stable economies 77 More generally, the fact that correlations and copulas disagree suggests

\footnotetext{
${ }^{76}$ Results of this test are available from the authors, upon request.

${ }^{77}$ For research on genericity, see Debreu (1970).
} 
correlation complexity. Hence, clear information about the economy's state is not always readily available for individuals, banks, and policymakers.

\section{Conclusions}

In this paper, we examine the dependence structure of important US macroeconomic variables. Motivated by theoretical and empirical considerations, we assess the tendency of macro variables to move together during extreme periods. We document four significant findings. First, correlations and copulas disagree substantially, which indicates complexity in the dependence structure of the US economy. Second, GDP exhibits linear dependence with interest rates and prices, but no extreme dependence with the latter. This suggests existence of liquidity traps during economic downturns. Third, GDP exhibits asymmetric extreme dependence with employment, consumption and investment, with relatively greater dependence in economic downturns. Fourth, money is neutral, especially during extreme economic conditions.

More broadly, our results add to the body of stylized facts about the US macroeconomy, by describing its dependence structure during both normal and extreme periods. Such policyrelevant information is largely unavailable using existing methods. Most significantly, our findings indicate that the US economic system is prone to simultaneous extreme events in multiple variables. From an academic perspective, these results are important for the theory and practice of economics, which typically assume generic existence of stable economies. From a policy perspective, our findings underscore the importance of using techniques that are robust to different economic situations, when measuring dependence in important macroeconomic and policy variables. 


\section{References}

Acharya, V., and M. Richardson, 2009, Restoring Financial Stability: How to Repair a Failed System. (John Wiley \& Sons, New York).

Adrian, T., and M. Brunnermeier, 2008, CoVaR: A systemic risk contribution measure, Working paper, Princeton University.

Ando, A., and F. Modigliani, 1963, The life cycle hypothesis of saving: aggregate implications and tests, American Economic Review 53, 55-84.

Ane, T., and C. Kharoubi, 2001, Dependence structure and risk measure, Journal of Business 76, 411-438.

Ang, Andrew, and Geert Bekaert, 2002, International Asset Allocation with Regime Shifts, Review of Financial Studies 15, 1137-87.

Ang, Andrew, and Joseph Chen, 2002, Asymmetric Correlations of Equity Portfolios, Journal of Financial Economics 63, 443-94.

Barberis, N., M. Huang, and T. Santos, 2001, Prospect theory and asset prices, Quarterly Journal of Economics CXVI, 1-53.

Barro, R., 2009, Rare Disasters, asset prices, and welfare costs, American Economic Review forthcoming.

Benartzi, S., and R. Thaler, 1995, Myopic loss aversion and the equity premium puzzle, Quarterly Journal of Economics 110, 73-92.

Bikhchandani, S., D. Hirschliefer, and I. Welch, 1992, A theory of fads, fashion, custom, and cultural change as informational cascades, Journal of Political Economy 100, 992-1026.

Brumelle, S., 1974, When does diversification between two investments pay?, Journal of Financial and Quantitative Analysis IX, 473-483.

Brunnermeier, M., 2009, Deciphering the liquidity and credit crunch of 2007-2008, Journal of Economic Perspectives 23, 77-100.

Burns, A., and W. Mitchell, 1946, Measuring Business Cycles. (National Bureau of Economic Research).

Caballero, R., and A. Krishnamurthy, 2008, Collective risk management in a flight to quality episode, Journal of Finance LXIII, 2195-2230. 
Cappiello, L., R. F. Engle, and K. Sheppard, 2006, Asymmetric dynamics in the correlations of global equity and bond returns, Journal of Financial Econometrics 4, 537-572.

Casella, G., and R. Berger, 1990, Statistical Inference. (Duxbury Press).

Chamberlain, G., 1983, A characterization of the distributions that imply mean-variance utility functions, Journal of Economic Theory 29, 185-201.

Chatterjee, S., and D. Corbae, 2007, On the aggregate welfare cost of Great Depression unemployment, Journal of Monetary Economics 54, 1529-1544.

Chen, X., and Y. Fan, 2006, Estimation and model selection of semiparametric copula-based multivariate dynamic models under copula misspecification, Journal of Econometrics 135, 125-154.

Cherubini, U., E. Luciano, and W. Vecchiato, 2004, Copula Methods in Finance. (Wiley West Sussex, England).

Chollete, L., A. Heinen, and A. Valdesogo, 2009, Modeling international financial returns with a multivariate regime-switching copula, Journal of Financial Econometrics forthcoming.

Cooper, R., 1999, Coordination Games: Complementarities and Macroeconomics. (Cambridge Press New York).

Danielsson, J., H. Shin, and J. Zigrand, 2009, Risk appetite and endogenous risk, Working paper, Princeton University.

de Haan, L., and A. Ferreira, 2006, Extreme Value Theory: An Introduction. (Springer).

de la Peña, V., R. Ibragimov, and S. Sharakhmetov, 2006, Characterizations of joint distributions, copulas, information, dependence and decoupling, with applications to time series, in J. Rojo, eds.: 2nd Erich Lehmann Symposium - Optimality: IMS Lecture Notes, Monograph Series 49 (Institute of Mathematical Statistics, Beachwood, $\mathrm{OH}$ ).

De Long, B., and L Summers, 1986, Are business cycles symmetrical?, in R. Gordon, eds.: The American Business Cycle: Continuity and Change (University of Chicago Press, Chicago ).

Debreu, G., 1970, Economies with a finite set of equilibria, Econometrica 38, 387-392.

Deheuvels, G., 1979, La function de dependance empirique et ses proprietes. Un test non parametriquen d'independance, Acad. Roy. Belg. Bull. C1. Sci. 65, 274-292.

Drouet Mari, D., and S. Kotz, 2001, Correlation and Dependence. (World Scientific Publishing Company).

Embrechts, P., 2009, Copulas: A personal view, Journal of Risk and Insurance forthcoming. 
Embrechts, P., C. Kluppelberg, and T. Mikosch, 1997, Modelling Extremal Events for Insurance and Finance. (Springer, Berlin).

Embrechts, P., A. McNeil, and R. Frey, 2005, Quantitative Risk Management: Concepts, Techniques and Tools. (Princeton University Press).

Embrechts, P., A. McNeil, and D. Straumann, 2002, Correlation and dependence in risk managament: Properties and pitfalls, in M. Dempster, eds.: Risk Management: Value at Risk and Beyond (Cambridge University Press, Cambridge, UK ).

Fama, E., 1965, The behavior of stock market prices, Journal of Business 38, 34-105.

Feldstein, M., and C. Horioka, 1980, Domestic saving and international capital flows, Economic Journal 90, 314-329.

Fermanian, Jean-David, and Olivier Scaillet, 2003, Nonparametric estimation of copulas for time series, The Journal of Risk 5, 25-54.

Forbes, K., and R. Rigobon, 2002, No Contagion, Only Interdependence: Measuring Stock Market Comovements, Journal of Finance 57, 2223-61.

Friedman, M., 1957, A Theory of the Consumption Function. (Princeton University Press).

Friedman, M., 1968, The role of monetary policy, American Economic Review 58, 1-17.

Gabaix, X., P. Gopikrishnan, V. Plerou, and H. Stanley, 2003, A theory of power-law distributions in financial market fluctuations, Nature 423, 267-270.

Genest, Christian, K. Ghoudi, and Louis-Paul Rivest, 1995, A Semiparametric Estimation Procedure of Dependence Parameters in Multivariate Families of Distributions, Biometrika 82, 543-552.

Granger, C., 2001, Overview of nonlinear macroeconometric empirical models, Macroeconomic Dynamics 5, 466-481.

Hall, R., 1988, Intertemporal substitution in consumption, Journal of Political Economy 96, 221273.

Hall, R., and D. Jorgenson, 1967, Tax policy and investment behavior, American Economic Review 57, 391-414.

Hamilton, J., 1983, Oil and the macroeconomy since World War II, Journal of Political Economy 91, 228-248.

Hamilton, J., 2001, A parametric approach to flexible nonlinear inference, Econometrica 69, 537573. 
Hansen, G., 1985, Indivisible labor and the business cycle, Journal of Monetary Economics 16, 309-327.

Hartmann, P., S. Straetmans, and C. de Vries, 2003, A Global Perspective on Extreme Currency Linkages, in W. C. Hunter, G. G. Kaufman, and M. Pomerleano, eds.: Asset Price Bubbles: Implications for Monetary, Regulatory and International Policies (MIT Press, Cambridge ).

Harvey, A., and F. Busetti, 2009, When is a copula constant? A test for changing relationships, Working paper, Cambridge University.

Harvey, A., and G. de Rossi, 2009, Quantiles, expectiles and splines, Journal of Econometrics forthcoming.

Harvey, Campbell R., and Akhtar Siddique, 1999, Autoregressive Conditional Skewness, Journal of Financial and Quantitative Analysis 34, 465-87.

Hodrick, R., and R. Prescott, 1997, Postwar US business cycles: an empirical investigation, Journal of Money, Credit and Banking 29, 1-16.

Horst, U., and J. Scheinkman, 2006, Equilibria in systems of social interactions, Journal of Economic Theory 130, 44-77.

Ibragimov, R., 2009, Heavy-tailed densities, in S. Durlauf, and L. Blume, eds.: The New Palgrave Dictionary of Economics Online (Palgrave Macmillan, ).

Ibragimov, R., D. Jaffee, and J. Walden, 2009a, Diversification disasters, Working paper, University of California at Berkeley.

Ibragimov, R., D. Jaffee, and J. Walden, 2009b, Non-diversification traps in catastrophe insurance markets, Review of Financial Studies 22, 959-993.

Jaffee, D., 2006, Monoline restrictions, with applications to mortgage insurance and title insurance, Review of Industrial Organization 28, 83-108.

Jaffee, D., and T. Russell, 1976, Imperfect information, uncertainty, and credit rationing, Quarterly Journal of Economics XC, 651-666.

Jaffee, D., and T. Russell, 1997, Catastrophe insurance, capital markets, and uninsurable risks, Journal of Risk and Insurance 64, 205-230.

Joe, Harry, 1997, Multivariate models and dependence concepts. (Chapman and Hall/CRC London; New York).

Jondeau, E., S. Poon, and M. Rockinger, 2007, Financial Modeling under Non-Gaussian Distributions. (Springer). 
Jondeau, E., and M. Rockinger, 2006, The copula-GARCH model of conditional dependencies: An international stock market application, Journal of International Money and Finance 25, 827-853.

Kahneman, D., and A. Tversky, 1979, Prospect theory: an analysis of decision under risk, Econometrica 47, 263-291.

Keynes, J., 1936, The General Theory of Employment, Interest and Money. (Harcourt, Brace, and Company).

Keynes, J., 1939, Relative movements of real wages and output, Economic Journal 49, 34-51.

King, R., and C. Plosser, 1984, Money, credit, and prices in a real business cycle, American Economic Review 74, 363-380.

Krishnamurthy, A., 2009, Amplification mechanisms in liquidity crises, Working paper, Northwestern University.

Kydland, F., and E. Prescott, 1982, Time to build and aggregate fluctuations, Econometrica 50, $1345-1370$.

Laxton, D., D. Rose, and D. Tambakis, 1999, The US Phillips curve: The case for asymmetry, Journal of Economic Dynamics and Control 23, 1459-1485.

Long, J., and C. Plosser, 1983, Real business cycles, Journal of Political Economy 91, 39-69.

Longin, F., and B. Solnik, 1995, Is the Correlation in International Equity Returns Constant: 19601990?, Journal of International Money and Finance 14, 3-26.

Longin, Francois, and Bruno Solnik, 2001, Extreme Correlation of International Equity Markets, Journal of Finance 56, 649-76.

Lucas, R., 1972, Expectations and the neutrality of money, Journal of Economic Theory 4, 103-124.

Lucas, R., 1973, Some international evidence on output-inflation tradeoffs, American Economic Review 63, 326-334.

Lucas, R., 1975, An equilibrium model of the business cycle, Journal of Political Economy 83, $1113-1144$

Lucas, R., 1977, Understanding business cycles, Carnegie-Rochester Conference Series on Public Policy 5, 7-29.

Lucas, R., and L. Rapping, 1969, Real wages, employment, and inflation, Journal of Political Economy $77,721-754$. 
Mandelbrot, B., 1963, The variation of certain speculative prices, Journal of Business 36, 394-419.

Mashal, R., and A. Zeevi, 2002, Beyond Correlation: Extreme Co-movements Between Financial Assets, Working paper, Columbia University.

Mikosch, T., 2006, Copulas: Tales and facts, Extremes 9, 3-20.

Minsky, H., 1982, Can it Happen Again? Essays on Instability and Finance. (M. E. Sharpe New York).

Mogstad, M., and M. Wiswall, 2009, Family size and children's education: How linear models can mask a nonlinear relationship, Working paper, New York University.

Nelsen, Roger B., 1998, An Introduction to Copulas. (Springer-Verlag New York, Inc. New York).

Ning, C., 2006, Dependence structure between the equity market and the foreign exchange market-a copula approach, Working paper, Ryerson University.

Ning, C., 2008, Extreme dependence of international stock market, Working paper, Ryerson University.

Okimoto, T., 2008, New evidence on asymmetric dependence structures in international equity markets, Journal of Financial and Quantitative Analysis, forthcoming.

Patton, A., 2004, On the Out-of-Sample Importance of Skewness and Asymmetric Dependence for Asset Allocation, Journal of Financial Econometrics 2, 130-168.

Patton, A., 2006, Modelling Asymmetric Exchange Rate Dependence, International Economic Review 47, 527-556.

Patton, A., 2009, Copula-based models for financial time series, in T. Andersen, R. Davies, J. Kreiss, and T. Mikosch, eds.: Handbook of Financial Time Series (Springer, ).

Phelps, E., 1968, Money-wage dynamics and labor market equilibrium, Journal of Political Economy 76, 678-711.

Phelps, E., 2007, Macroeconomics for a modern economy, American Economic Review 97, 543561.

Phillips, A., 1958, The relation between unemployment and the rate of change of money wage rates in the United Kingdom, 1861-1957, Economica XXV, 283-299.

Polkovnichenko, V., 2005, Household Portfolio Diversification: A Case for Rank-Dependent Preferences, Review of Financial Studies 18, 1467-1501. 
Poon, S., M. Rockinger, and J. Tawn, 2004, Extreme value dependence in financial markets: Diagnostics, models, and financial implications, Review of Financial Studies 17, 581-610.

Rachev, S., 2003, Handbook of Heavy Tailed Distributions in Finance. (North Holland).

Reinhart, C., 2008, 800 years of financial folly, Working paper, University of Maryland.

Reinhart, C., and K. Rogoff, 2009, The aftermath of financial crises, American Economic Review forthcoming.

Rodriguez, J., 2007, Measuring financial contagion: A copula approach, Journal of Empirical Finance $14,401-423$.

Romer, D., 2001, Advanced Macroeconomics. (McGraw-Hill New York, NY).

Rosenberg, J., and T. Schuermann, 2006, A general approach to integrated risk management with skewed, fat-tailed risks, Journal of Financial Economics 79, 569-614.

Rothman, P., D. van Dijk, and P. Franses, 2001, Multivariate STAR analysis of money-output relationship, Macroeconomic Dynamics 5, 506-532.

Samuelson, P., 1967, General proof that diversification pays, Journal of Financial and Quantitative Analysis March, 1-13.

Sargent, T., 1979, Macroeconomic Theory. (Academic Press).

Schweizer, B., and E. F. Wolff, 1981, On Nonparametric Measures of Dependence for Random Variables, The Annals of Statistics 9, 879-885.

Shin, H., 2009, Securitisation and system stability, Economic Journal 119, 309-322.

Sklar, Abraham, 1959, Fonctions de repartition a n dimensions et leurs marges, Pub. Inst. Statist. Univ. Paris 8, 229-231.

Solon, G., R. Barsky, and J. Parker, 1994, Measuring the cyclicality of real wages: How important is composition bias?, Quarterly Journal of Economics 109, 1-25.

Stiglitz, J., and A. Weiss, 1981, Credit rationing in markets with imperfect information, American Economic Review 71, 393-410.

Taylor, J., 1993, Discretion versus policy rules in practice, Carnegie-Rochester Conference Series on Public Policy 39, 6195-214.

Veldkamp, L., and S. Van Nieuwerburgh, 2006, Learning asymmetries in real business cycles, Journal of Monetary Economics 53, 753-772. 
Veldkamp, L., and J. Wolfers, 2007, Aggregate shocks or aggregate information? Costly information and business cycle comovement, Journal of Monetary Economics 54, 37-55.

Vives, X., 2008, Information and Learning in Markets: The Impact of Market Microstructure. (Princeton Press).

Wilson, R., 1975, Informational economies of scale, Bell Journal of Economics 6, 184-195. 


\section{Table 1: Correlations between GDP and Other Macro Variables}

\begin{tabular}{|c|c|c|c|c|c|}
\hline \multicolumn{6}{|c|}{ Panel A: From monthly data } \\
\hline & GDP-Interest & GDP-Price & GDP-Emp. & GDP- Wage & GDP-Cons. \\
\hline \multirow[t]{2}{*}{ Linear corr. } & $0.2564 * *$ & $-0.2344 * *$ & $0.3591^{* *}$ & $0.1254 * *$ & $0.2379 * *$ \\
\hline & $(<0.0001)$ & $(<0.0001)$ & $(<0.0001)$ & $(0.0035)$ & $(<0.0001)$ \\
\hline \multirow[t]{2}{*}{ Spearman rho } & $0.1623 * *$ & $-0.1754 * *$ & $0.3462 * *$ & $0.1151 * *$ & $0.2427 * *$ \\
\hline & $(0.0002)$ & $(<0.0001)$ & $(<0.0001)$ & $(0.0075)$ & $(<0.0001)$ \\
\hline \multirow[t]{2}{*}{ Kendall's tau } & $0.1086^{* *}$ & $-0.1204 * *$ & $0.2453^{* *}$ & $0.0799 * *$ & $0.1662 * *$ \\
\hline & $(0.0002)$ & $(<0.0001)$ & $(<0.0001)$ & $(0.0055)$ & $(<0.0001)$ \\
\hline \multicolumn{6}{|c|}{ Panel B: Quarterly data } \\
\hline \multirow{3}{*}{ Linear corr. } & GDP-Interest & GDP-Price & GDP-Emp. & GDP- Wage & GDP-Cons. \\
\hline & $0.3390 * *$ & $-0.2970 * *$ & $0.5752 * *$ & $0.2188 * *$ & $0.6690 * *$ \\
\hline & $(<0.0001)$ & $(<0.0001)$ & $(<0.0001)$ & $(0.0033)$ & $(<0.0001)$ \\
\hline \multirow[t]{2}{*}{ Spearman rho } & $0.2499 * *$ & $-0.2396^{* *}$ & $0.5060 * *$ & $0.2316^{* *}$ & $0.5824 * *$ \\
\hline & $(0.0008)$ & $(0.0013)$ & $(<0.0001)$ & $(0.0019)$ & $(<0.0001)$ \\
\hline \multirow[t]{2}{*}{ Kendall's tau } & $0.1742 * *$ & $-0.1659 * *$ & $0.3611^{* *}$ & $0.1569 * *$ & $0.4253^{* *} *$ \\
\hline & $(0.0005)$ & $(0.0010)$ & $(<0.0001)$ & $(0.0018)$ & $(<0.0001)$ \\
\hline
\end{tabular}

in parentheses are p-values. ${ }^{*}$ stands for statistical significance at the $5 \%$ level.

Table 2: Correlations between Money and Other Macro Variables

\begin{tabular}{|c|c|c|}
\hline \multicolumn{3}{|c|}{ Panel A. Monthly data } \\
\hline & $M 1-E m p$ & $M 1-G D P$ \\
\hline \multirow[t]{2}{*}{ Pearson corr. } & -0.0101 & $-0.1342 * *$ \\
\hline & $(0.8157)$ & $(0.0018)$ \\
\hline \multirow[t]{2}{*}{ Spearman rho } & 0.0200 & -0.0465 \\
\hline & $(0.6431)$ & $(0.2816)$ \\
\hline \multirow{2}{*}{ Kendall's tau } & 0.013 & -0.0308 \\
\hline & $(0.6621)$ & $(0.2856)$ \\
\hline \multicolumn{3}{|c|}{ Panel B. Quarterly data } \\
\hline & $M 1-E m p$ & $M 1-G D P$ \\
\hline \multirow[t]{2}{*}{ Pearson corr. } & -0.0427 & 0.0017 \\
\hline & $(0.5703)$ & $(0.9817)$ \\
\hline \multirow[t]{2}{*}{ Spearman rho } & 0.0590 & 0.0875 \\
\hline & $(0.4326)$ & $(0.2440)$ \\
\hline \multirow[t]{2}{*}{ Kendall's tau } & 0.0380 & 0.0530 \\
\hline & $(0.4511)$ & $(0.2924)$ \\
\hline & employment & Numbers in \\
\hline
\end{tabular}


Table 3: Correlations between Inflation and Other Macro Variables

\begin{tabular}{ccc}
\hline Panel A. Monthly data & \\
& Inflation-Emp. & Inflation-GDP \\
Linear corr. & $0.1176^{* *}$ & $0.1321^{* *}$ \\
& $(0.0063)$ & $(0.0021)$ \\
Spearman's rho & $0.0990^{* *}$ & $0.0925^{* *}$ \\
& $(0.0216)$ & $(0.0318)$ \\
Kendall's tau & $0.0676^{* *}$ & $0.0613 * *$ \\
& $(0.0228)$ & $(0.0333)$ \\
\hline Panel B. Quarterly data & \\
Pearson corr. & Inflation-Emp. & Inflation-GDP \\
& $0.2609 * *$ & $0.1355^{* *}$ \\
Spearman rho & $(0.0004)$ & $(0.0706)$ \\
& $0.1797 * *$ & 0.0199 \\
Kendall's tau & $(0.0161)$ & $(0.7918)$ \\
& $0.1249 * *$ & 0.0134 \\
& $(0.0132)$ & $(0.7914)$ \\
\hline
\end{tabular}

Emp. denotes the employment rate. Numbers in parentheses are p-values. ${ }^{* *}$ stands for statistical significance at the $5 \%$ level.

Table 4: Correlations between Investment and GDP

\begin{tabular}{cccc}
\hline & Linear corr. & Spearman's rho & Kendall's tau \\
Investment-GDP & $0.7883^{* *}$ & $0.7497^{* *}$ & $0.5649 * *$ \\
& $(<0.0001)$ & $(<0.0001)$ & $(<0.0001)$ \\
\hline
\end{tabular}

Numbers in parentheses are p-values. $* *$ stands for statistical significance at the $5 \%$ level. The frequency is quarterly. 
Table 5: Tail dependence: GDP and Other Macro Variables

\begin{tabular}{|c|c|c|c|c|c|c|}
\hline \multicolumn{7}{|c|}{ Panel A: Monthly data } \\
\hline & GDP-Interest & GDP-Neg. Interest & GDP-Price & GDP-Emp. & GDP- Wage & GDP-Cons. \\
\hline \multirow[t]{2}{*}{$\lambda_{l}$} & 0.2044 & 0.0000 & 0.0819 & $0.1952 * *$ & 0.0519 & $0.1864 * *$ \\
\hline & $(0.6609)$ & $(5.0553)$ & $(0.8565)$ & $(0.0581)$ & $(0.0454)$ & $(0.0493)$ \\
\hline \multirow[t]{2}{*}{$\lambda_{r}$} & 0.0000 & 0.0000 & 0.0000 & $0.1132 * *$ & 0.0303 & $0.009^{* *}$ \\
\hline & $(1.0376)$ & $(5.0553)$ & $(1.2951)$ & $(0.063)$ & $(0.0418)$ & $(<0.0001)$ \\
\hline AIC & -9.0829 & 7.1124 & -1.7335 & -57.056 & -14.5406 & -36.4694 \\
\hline BIC & -0.5035 & 15.6918 & 6.8459 & -48.4766 & -5.9612 & -27.8899 \\
\hline \multicolumn{7}{|c|}{ Panel B: Quarterly data } \\
\hline & GDP-Interest & GDP-Neg. Interest & GDP-Price & GDP-Emp. & GDP- Wage & GDP-Cons. \\
\hline \multirow[t]{2}{*}{$\lambda_{l}$} & $0.2691 * *$ & 0.0000 & 0.1724 & $0.4905^{* *}$ & $0.1833 * *$ & $0.4392 * *$ \\
\hline & $(0.0847)$ & $(5.0557)$ & $(0.7861)$ & $(0.0573)$ & $(0.0903)$ & $(0.0704)$ \\
\hline \multirow[t]{2}{*}{$\lambda_{r}$} & 0.0426 & 0.0000 & 0.0000 & $0.2479 * *$ & 0.0591 & $0.4235^{* *} *$ \\
\hline & $(0.1021)$ & $(5.0557)$ & $(1.2302)$ & $(0.1098)$ & $(0.1006)$ & $(0.0756)$ \\
\hline AIC & -19.5044 & 5.7302 & 0.7241 & -70.2723 & -11.3581 & -81.718 \\
\hline $\mathrm{BIC}$ & -13.1296 & $(12.1050)$ & 7.0989 & -63.8975 & -4.9833 & -75.3433 \\
\hline
\end{tabular}

Table 6: Tail dependence: Money and Other Macro Variables

\begin{tabular}{|c|c|c|}
\hline \multicolumn{3}{|c|}{ Panel A: Monthly data } \\
\hline & M1-Employment & M1-GDP \\
\hline \multirow[t]{2}{*}{$\lambda_{l}$} & 0.0000 & 0.0000 \\
\hline & $(5.0561)$ & $(5.0554)$ \\
\hline \multirow[t]{2}{*}{$\lambda_{r}$} & 0.0000 & 0.0000 \\
\hline & $(5.0561)$ & $(5.0554)$ \\
\hline AIC & 4.1881 & 5.0198 \\
\hline $\mathrm{BIC}$ & 12.7675 & 13.5992 \\
\hline \multicolumn{3}{|c|}{ Panel B: Quarterly data } \\
\hline & M1-Employment & M1-GDP \\
\hline \multirow[t]{2}{*}{$\lambda_{l}$} & 0.0000 & 0.027 \\
\hline & $(8.8119)$ & $(1.4356)$ \\
\hline \multirow[t]{2}{*}{$\lambda_{r}$} & 0.0000 & 0.0000 \\
\hline & $(4.6804)$ & $(1.3089)$ \\
\hline AIC & 3.9651 & 3.7581 \\
\hline BIC & 10.3399 & 10.1329 \\
\hline
\end{tabular}


Table 7: Tail dependence: Inflation and Other Macro Variables

\begin{tabular}{|c|c|c|}
\hline \multicolumn{3}{|c|}{ Panel A: Monthly data } \\
\hline & Inflation-Emp. & Inflation-GDP \\
\hline \multirow[t]{2}{*}{$\lambda_{l}$} & $0.036^{* *}$ & 0.1589 \\
\hline & $(<0.0001)$ & $(1.0736)$ \\
\hline \multirow[t]{2}{*}{$\lambda_{r}$} & 0.0000 & 0.0000 \\
\hline & $(<0.0001)$ & $(1.3347)$ \\
\hline AIC & -0.358 & 0.9597 \\
\hline $\mathrm{BIC}$ & 8.2214 & 9.5391 \\
\hline \multicolumn{3}{|c|}{ Panel B: Quarterly data } \\
\hline & Inflation-Emp. & Inflation-GDP \\
\hline \multirow[t]{2}{*}{$\lambda_{l}$} & 0.4090 & 0.0958 \\
\hline & $(0.6516)$ & $(0.7665)$ \\
\hline \multirow[t]{2}{*}{$\lambda_{r}$} & 0.0000 & 0.0000 \\
\hline & $(1.0372)$ & $(1.1077)$ \\
\hline AIC & -1.7116 & 2.0904 \\
\hline $\mathrm{BIC}$ & 4.6632 & 8.4652 \\
\hline
\end{tabular}

Table 8: Tail dependence: Investment and GDP

\begin{tabular}{ccccc}
\hline \multirow{3}{*}{ GDP-Investment } & $\lambda_{l}$ & $\lambda_{r}$ & $\mathrm{AIC}$ & $\mathrm{BIC}$ \\
& $0.5948^{* *}$ & $0.5756^{* *}$ & -153.3120 & -146.9380 \\
& $(0.0494)$ & $(0.0540)$ & & \\
\hline
\end{tabular}

Numbers in parentheses are standard errors. ${ }^{* *}$ stands for statistical significance at the $5 \%$ level. The frequency is quarterly. 